\title{
Assessment of Electricity-Free Hydroponics in India: A Proof of Concept Field Study
}

\author{
Indira Roy ${ }^{1}$, Yelena Naumova ${ }^{1} \&$ A. J. Both ${ }^{2}$ \\ ${ }^{1}$ Chatham High School, Chatham, NJ, USA \\ ${ }^{2}$ Department of Environmental Sciences, Rutgers University, New Brunswick, NJ, USA \\ Correspondence: Indira Roy, Chatham High School, 255 Lafayette Avenue, Chatham, NJ 07928, USA. Tel: \\ 1-973-944-1300. E-mail: induroy2000@gmail.com
}

Received: October 5, 2017

Accepted: November 8, 2017 Online Published: December 15, 2017

doi:10.5539/jas.v10n1p45

URL: https://doi.org/10.5539/jas.v10n1p45

\begin{abstract}
Subsistence and smallholder farmers in the Deccan plateau region of India struggle with a predominantly hot and dry climate and often accumulated debt due to the cost of fertilizer that they need to increase yields for profitability. While a low-cost deep-flow technique hydroponic growing system (DFT) as a supplement to soil-based agriculture could help reduce debt, the cost of electricity needed to operate the DFT makes it inaccessible to these farmers. The objective of this project was to test the viability of electricity-free DFT which would substantially reduce production costs. Two DFT systems were set up in a shade net house and prepared with identical nutrients to grow chili pepper seedlings. Each DFT system was oxygenated for 30 minutes per day, one system using an electrical air pump, and the other system was oxygenated manually. After four weeks of growth, the dry mass of the shoots of the chili pepper seedlings in each system was measured. While the pump-oxygenated DFT system produced more dry matter, the manually-oxygenated system produced a larger number of visually healthier plants. Therefore, we conclude that electricity-free DFT hydroponics may be a viable alternative to pump-oxygenated DFT hydroponics, making hydroponic farming a cost-effective option for poor farmers.
\end{abstract}

Keywords: controlled environment agriculture, electricity-free, food security, hydroponics, subsistence farmers

\section{Introduction}

This paper focuses on Andhra Pradesh (AP) and Telangana, two Indian states that currently share the city of Hyderabad as their capital (Government of Telangana, 2017; Government of India, 2017). AP and Telangana have predominantly semi-arid or arid climates (Baumann, 2008), red loam or sandy loam soil (Majumdar, 2015), as well as frequent droughts (Jensen \& Malter, 1995). Despite these conditions, 62\% of AP and Telangana's combined population is involved in agriculture (Government of India, 2016), and in 2009 the two states produced approximately $57 \%$ of India's chili peppers, equaling $21 \%$ of the world's total chili pepper production for that year (Government of India, 2009), making the region a primarily agricultural economy. The large production of chili peppers has not resulted, however, in financial security for the farmers. In order to make cultivation possible, many farmers spend $35 \%$ of the total cultivation costs on expensive chemical fertilizers and pesticides, and often go into debt when the crop yield is insufficient to offset their production costs. As a consequence, $82 \%$ of farmers in AP and Telangana are in perpetual debt, and the average outstanding debt for these farmers is two times the national average (Larson \& Williams, 2012). Apart from reducing poverty in general, reducing farmers' debts may save lives, as a large number of Indian farmers commit suicide due to the spiraling burden of debt (Pokharel, 2015).

Reducing farmers' debt requires altering their agricultural practices. A logical approach would be to reduce the cost of chemical fertilizer and pesticides. Hydroponics, a soilless plant production technique that requires an inert substrate and a nutrient solution to grow plants, can significantly reduce the cost of chemical fertilizers because a limited quantity of chemical nutrients are used in the growing solution. When hydroponic systems are placed in controlled environments, the threat of crop damage due to pests, fungi, and bacteria is reduced, reducing the need for chemical pesticides (Shrestha \& Dunn, 2016). Other benefits of using hydroponics in AP and Telangana are the ability to produce adequate crop yield without depending on soil quality, a useful ability in a region with infertile soils, and the reduced water requirement (in addition to the recirculation of nutrient solution, which further lowers the water usage), which can also be critically beneficial in this drought-prone region (Jensen \& Malter, 1995). In addition, hydroponically-grown crops typically have a greater yield per unit area than crops grown in soil 
(Shrestha \& Dunn, 2016) because hydroponically-grown crops can be grown and harvested many times in a year, whereas crops grown in the field can only be harvested up to a few times per year. This is helpful for farmers in AP and Telangana, as $80 \%$ of farming households in the two states have fewer than 2 hectares of land (Garcia et al., 2006), or less than half the Indian national average of 5 hectares (Qaim \& Kouser, 2013).

Hydroponic farming in parts of India, however, is considered prohibitive in terms of the high cost of electricity needed to maintain a successful hydroponic system (Kubota \& Kroggel, 2015), especially in regions with inconsistent supply of electricity and inadequate infrastructure. As such, hydroponics can only be a viable solution for smallholder and subsistence farmers in AP and Telangana if the need for electricity is eliminated as a key barrier among other potential challenges to enable productive farming. As a first step in that direction, the purpose of this study was to test the conceptual feasibility of conducting low-cost, electricity-free hydroponic farming in this region by comparing the productivity of a manually-operated hydroponic system with a conventional electricity-based system.

\section{Methods}

\subsection{Study Approach}

This study was conducted on a small plot of land in the outskirts of Hyderabad, the capital city of the region. The setting was representative of what a typical smallholder or subsistence farmer has access to with minimal financial or infrastructural support from the government or other outside organizations. It was conducted during the summer months (end of June through the beginning of August) of 2016 and was representative of the usual, generally adverse, climate and water availability conditions faced by smallholder and subsistence farmers.

Although not set up as a confirmatory experiment, this "proof of concept" study utilized two identical deep flow technique (DFT) hydroponic systems to compare the yields of two groups of plants grown with and without the use of electricity. A conventional DFT system oxygenated using an electrical air pump (Figure 1) and a modified DFT system oxygenated manually (Figure 2) were custom built for the purposes of the study. Each system had the dimensions $2.7 \mathrm{~m} \times 2.1 \mathrm{~m} \times 0.3 \mathrm{~m}$ and contained a total solution volume of $1600 \mathrm{~L}$. The DFT system tanks were built using bricks, sand, and cement, then covered in tarpaulin to prevent the solution from leaking into the ground. The conventional DFT system included a tank containing the nutrient solution, raft beds floating on the surface of the solution, and a Boyu brand ACQ-003 electromagnetic air compressor (manufactured by the Guangdong Boyu Group located in Chaozhou, China) to oxygenate the nutrient solution. Air lines and air stones were used to distribute air from the pump throughout the tank. The modified DFT system, on the other hand, did not include the air pump, air lines, or air stones, and was oxygenated manually. The use of electricity for oxygenation was the only factor that was different between the two DFT system set-ups thus providing for a semi-controlled environment for a comparative study design.

The effective oxygenation of the DFT systems was crucial to this study because oxygenation maintains the dissolved oxygen concentration in the nutrient solution, and this oxygen is necessary for successful root growth and development. A lack of oxygen could lead to the buildup of carbon dioxide, ethylene gas, and organic acids within the system, impairing overall plant growth as well (Goto et al., 1997). Various conditions can affect the dissolved oxygen concentration of a volume of water, including the temperature, $\mathrm{pH}$, and movement (agitation) of the water (US Geological Survey, 2017). During this study, the temperature and $\mathrm{pH}$ were kept constant so that the effect of the dissolved oxygen concentration of the nutrient solution (comparing the effect of an air pump versus manual oxygenation) could be studied. When the temperature and $\mathrm{pH}$ of a volume of water is kept constant, greater agitation of water typically results in a higher dissolved oxygen concentration (US Geological Survey, 2017).

The hypothesis of this study was that the two forms of oxygenation would result in similar yield and productivity, indicating that the use of an electricity-free modified DFT system can be viable, and therefore making it more cost-effective and accessible to smallholder and subsistence farmers in rural India. 


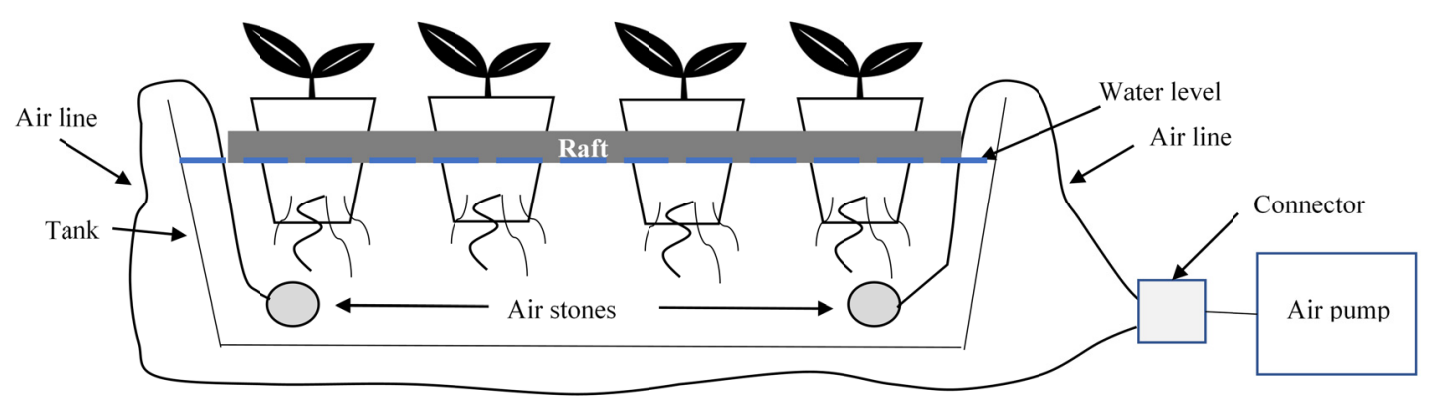

Figure 1. In a conventional DFT system, the air pump is connected to a power source. The air from the pump flows through the air lines and the air stones allow for small bubbles that spread throughout the tank. Rafts (typically made of Styrofoam ${ }^{\mathrm{TM}}$ boards) float on the surface of the nutrient solution and allow plants' roots to grow downwards so that they receive the nutrients and oxygen necessary for growth and development

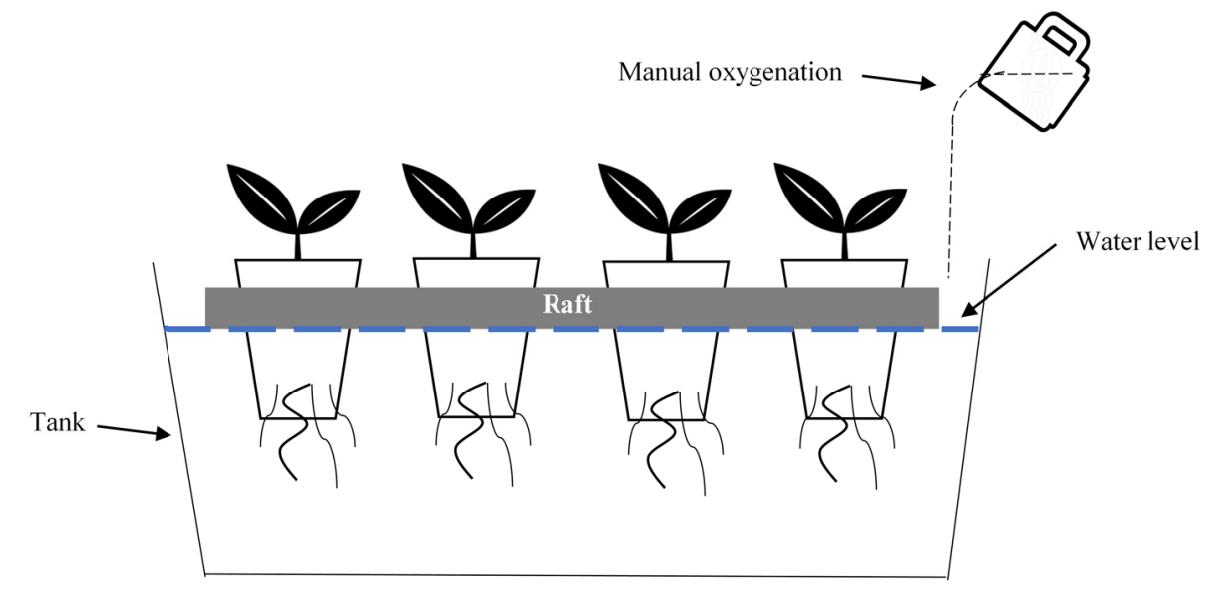

Figure 2. The modified DFT system lacks the air pump, air lines, and air stones used in the conventional DFT system. This makes the modified DFT system electricity-free

\subsection{DFT System Set-Up}

The conventional and modified DFT systems were constructed side-by-side inside a $4.5 \mathrm{~m} \times 9.0 \mathrm{~m} \times 2.4 \mathrm{~m}$ (W $\times$ $\mathrm{L} \times \mathrm{H}$ ) shade net house, thus ensuring exposure to the exact same climatic conditions (Figures 3 and 4). The shade net house was built at a location with coordinates 17.160091 degrees North and 78.133122 degrees East and an elevation of $650 \mathrm{~m}$ above sea level. The DFT tanks were each filled with equal amounts of nutrient solution. The composition of the nutrient solution was based on a recipe described by Mattson and Peters (2014). The solution contained Solucros brand potassium sulfate, Jai Kisaan brand monoammonium phosphate, Nagarjuna brand neem-coated urea, Jai Kisaan brand calcium nitrate, and Rexolin brand CXK-II EDTA microgranules. The composition of the micronutrients in the granules was $1.5 \%$ boron, $0.5 \%$ copper, $3.4 \%$ iron, $1.2 \%$ magnesium, 3.2\% manganese, $0.05 \%$ molybdenum, $4.2 \%$ zinc (Table 1). $0.49 \mathrm{~m} \times 0.99 \mathrm{~m} \times 0.02 \mathrm{~m}$ Styrofoam rafts were placed on the surface of the nutrient solution. This resulted in a spacing of 160 net pots per square meter. 
Table 1. Composition of the nutrient solution used

\begin{tabular}{ll}
\hline Nutrient & Concentration $\mathbf{( p p m )}$ \\
\hline Potassium sulfate & 281 \\
Monoammonium phosphate & 47 \\
Neem-coated urea & 224 \\
Calcium nitrate & 212 \\
Boron & 0.28 \\
Copper & 0.05 \\
Iron & 2 \\
Magnesium & 65 \\
Manganese & 0.55 \\
Molybdenum & 0.05 \\
Zinc & 0.33 \\
\hline
\end{tabular}

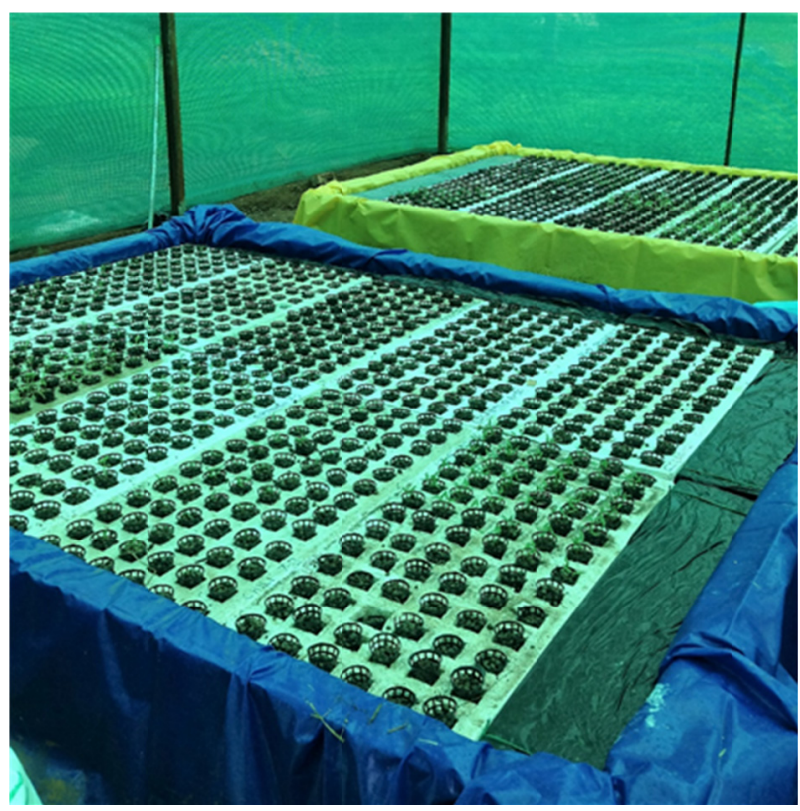

Figure 3. The conventional DFT system, in blue, is located next to the modified DFT system, in yellow. Both are in the semi-controlled environment within the shade net house. This photograph was taken on the day the seedlings were transferred into the DFT systems

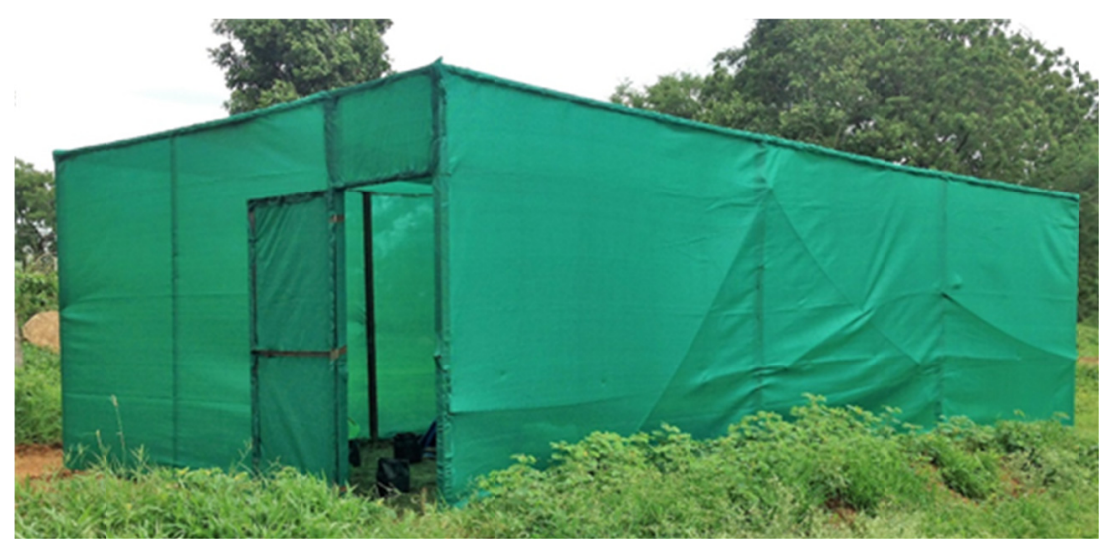

Figure 4. The shade net house provided a semi-controlled environment for the two DFT systems 
The air pump utilized during the experiment was a Boyu brand ACQ-003 electromagnetic air pump. The pump required $35 \mathrm{~W}$ of power (obtained from the local grid) and had an output of $50 \mathrm{~L} / \mathrm{min}$.

All materials for building the systems were procured locally to ensure they would be accessible to local farmers. In addition, labor utilized for construction were local farmers who were exposed to the process to establish an initial conceptual validation of the technical feasibility of building such a system on a larger scale.

\subsection{Plant Production}

In view of the local climate, the relatively short crop cycle, and the local popularity, chili peppers were selected as the test crop for this "proof of concept" study. Five chili pepper seeds were first seeded in a covered outdoor area neighboring the shade net house into one of 392 net pots containing expanded clay pellets to allow germination (Figure 5). Before germination, the rafts containing net pots were kept outdoors (beneath a metal roof to protect from possible rain) under an opaque mulching sheet. For the first five days after seeding, each raft (which contained 78 net pots) was given $1.5 \mathrm{~L}$ of water. For the following three days, after a majority of the net pots contained germinated seedlings, the mulching sheet was removed and each raft was given $2.5 \mathrm{~L}$ of water. The next day, the rafts were moved to the shade net house to accustom the seedlings to any environmental differences between the outdoor space and the shade net house. Each raft was given $2.5 \mathrm{~L}$ of water that day. For the next two days, each raft was given $3.5 \mathrm{~L}$ of water because the growing seedlings began to require more water. The care for the seedlings was essential to allow for the growth of the plants' roots before they could utilize the nutrient solution in the DFT hydroponic systems.

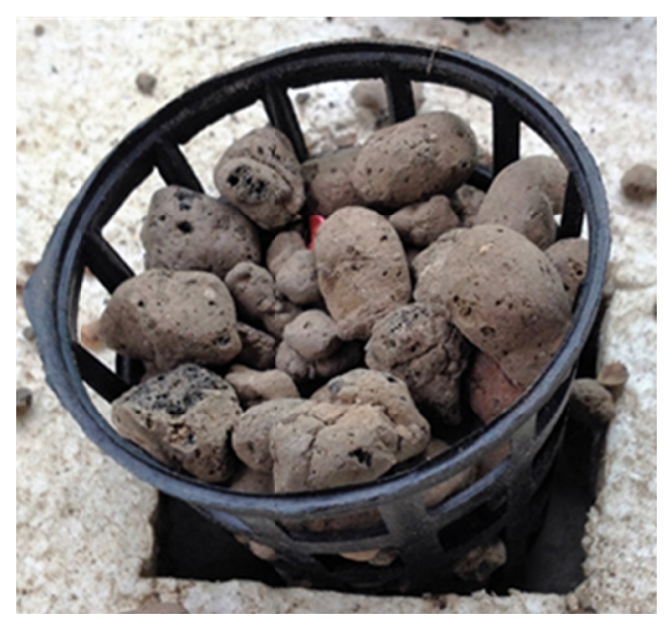

Figure 5. Net pots were filled with a clay pellet growing medium. The red particle visible is a seed

Meanwhile, raft beds (as shown in Figures 1 and 2) were prepared by manually cutting out $4.7 \mathrm{~cm} \times 4.4 \mathrm{~cm}$ holes in the Styrofoam ${ }^{\mathrm{TM}}$ boards to place the net pots in. After ten days of growth, 172 net pots contained successfully germinated chili pepper seedlings that were placed in the raft beds (the remainder of the net pots were discarded), and then the remaining surface area of the solution exposed to sunlight was covered with additional Styrofoam sheets to prevent the growth of algae. (Notwithstanding, algae growth did occur after two weeks.)

The two systems were each oxygenated for 30 minutes at approximately 11:30 A.M. each morning. The schedule for oxygenation was based on advice from a local advisor involved in commercial agriculture. The conventional DFT system was oxygenated using the electrical air pump, while the modified DFT system was oxygenated manually. To ensure consistency, one researcher was trained in the process of manual oxygenation, which involved scooping out about $2 \mathrm{~L}$ of nutrient solution in a pitcher, lifting the pitcher to a height of about $0.4 \mathrm{~m}$ above the surface of the solution, and then pouring the solution back into the tank, without direct contact with the seedlings (Figure 5). The manual oxygenation method was chosen to mimic the output of the air pump. The pump had an output of $50 \mathrm{~L} / \mathrm{min}$, and the manual oxygenation involved pouring $2 \mathrm{~L}$ of water at a time and this process was repeated approximately 5 times per minute. This means that the pump and the manual oxygenation did not necessarily have the same performance, but the study compared the pump's performance to that of reasonable human performance.

The $\mathrm{pH}$, temperature, and electrical conductivity (EC) of the nutrient solutions in the two tanks were also measured once daily, immediately before oxygenation. The $\mathrm{pHs}$ of the two tanks were measured using a Bluelab brand $\mathrm{pH}$ 
pen (manufactured by Bluelab Corporation Limited located in Tauranga, New Zealand) and over the course of four weeks remained almost constant at a level of $6.7 \pm 0.1$. The temperatures also remained approximately constant at $27 \pm 1{ }^{\circ} \mathrm{C}$. The EC of the tanks varied over time. The EC of the nutrient solution in each system was initially 3.1 $\mathrm{dS} / \mathrm{m}$, then spiked as high as $4.2 \mathrm{dS} / \mathrm{m}$, and by the end of the four-week growth period, the ECs varied somewhat, as the EC of the nutrient solution in the conventional DFT system was $2.5 \mathrm{dS} / \mathrm{m}$, while the EC of the nutrient solution in the modified DFT system was $2.9 \mathrm{dS} / \mathrm{m}$ (Figure 6).

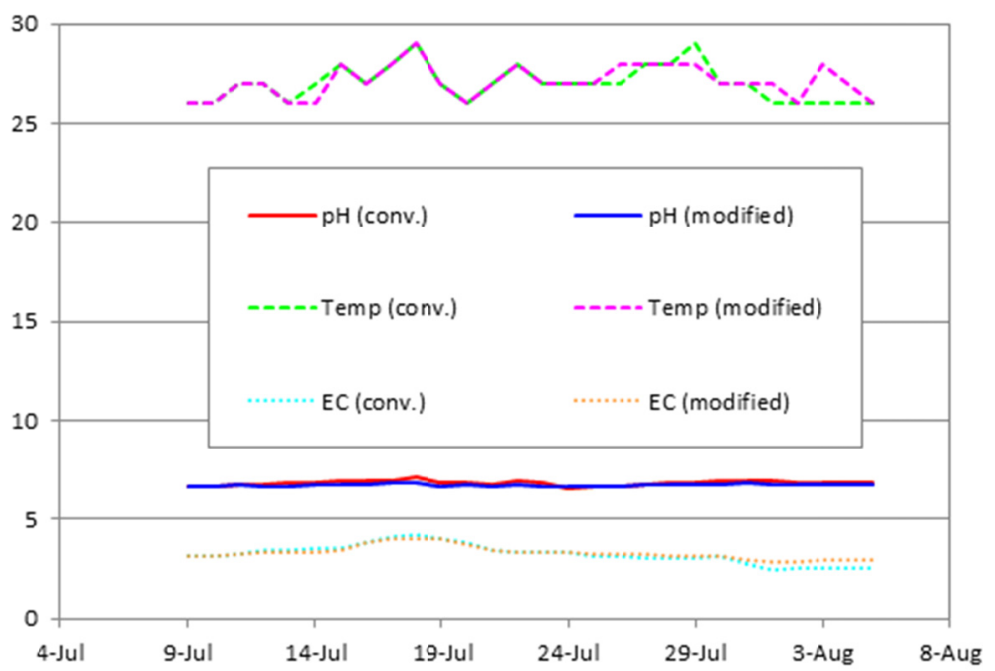

Figure 6. The values over time of the $\mathrm{pH}$, temperature $\left({ }^{\circ} \mathrm{C}\right)$, and $\mathrm{EC}(\mathrm{dS} / \mathrm{m})$ for the conventional and modified systems

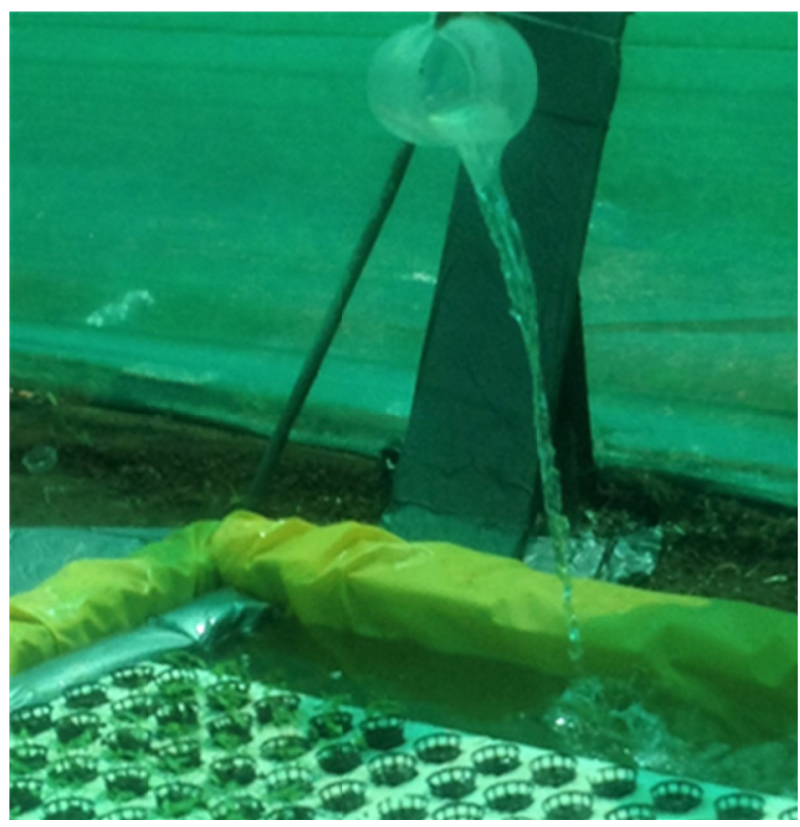

Figure 7. The modified DFT system was oxygenated by scooping out water and pouring it back into the tank, without making direct contact with the plants

\subsection{Measurement}

The oxygenation and other study activities were continued for four weeks. Although this was not sufficient time to complete the full crop cycle of 16 weeks (Bosland \& Walker, 2014), it was considered sufficient for the assessment of relative differences in growth and yield between the two groups because the period of rapid green chili pepper 
plant growth ends after four weeks (Bosland \& Walker, 2014) and the plants, while they do not yet have fruit, approach maturity. Figure 8 shows the state of the crop at the time of harvest within this study. After the four-week period, the dry shoot mass of the total crop yield from each DFT system was determined.

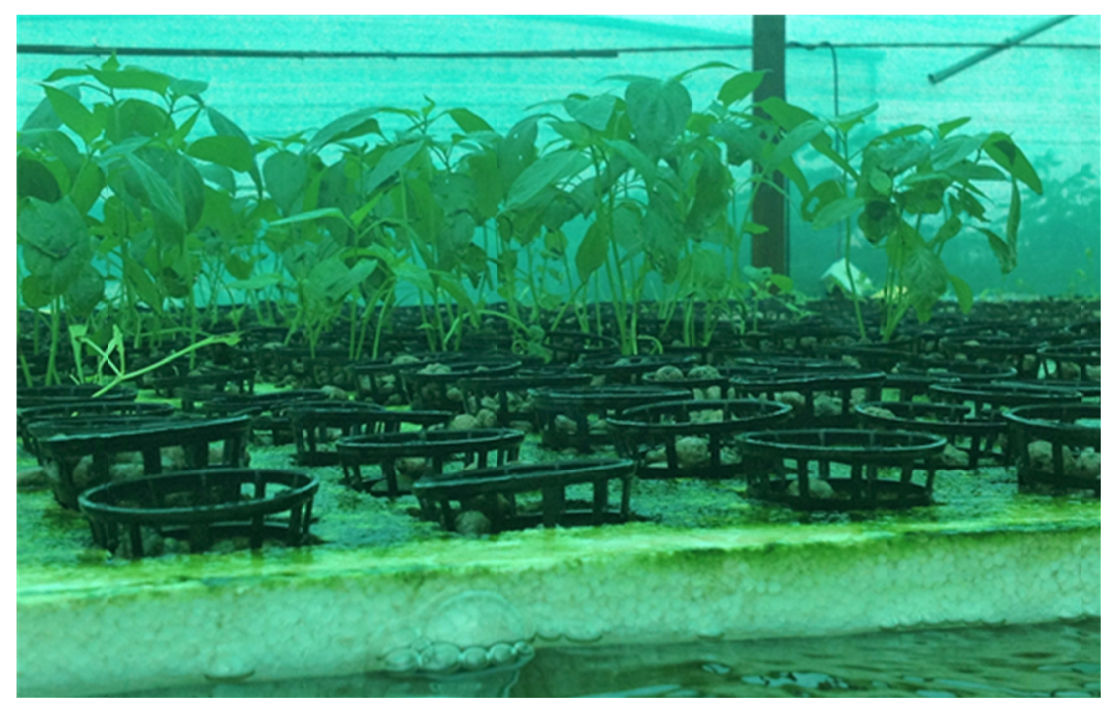

Figure 8. Plants growing in the modified DFT system. The chili pepper plants in either system did not produce fruit by the time of the conclusion of the experiment

An NPK (nitrogen, phosphorus, and potassium) analysis of crop samples grown in each DFT system was also conducted at a nearby state agricultural university's research center through a rigorous, multi-step process. First, the crop samples were thoroughly washed and cleaned to remove any external impurities that could affect the results, then the water was slowly removed from the samples by placing them in a drying oven at $70{ }^{\circ} \mathrm{C}$ for several days, then the dried samples were crushed into a powder.

To find the concentration of potassium in the sample, $2.0 \mathrm{~g}$ of each powder was mixed with a solution containing $9.0 \mathrm{~mL}$ of nitric acid, $3.0 \mathrm{~mL}$ hydrochloric acid, and $1.0 \mathrm{~mL}$ perchlorate and kept overnight. The mixtures were heated to $100{ }^{\circ} \mathrm{C}$ for 4 hours to reduce the volume to $1.0 \mathrm{~mL}$. The remaining mixture was then cooled and filtered through filter paper with distilled water. The filtrate was then diluted with distilled water to form a $100.0 \mathrm{~mL}$ solution. $1.0 \mathrm{~mL}$ of the diluted solution was then placed in a flame photometer to determine the concentration of potassium in the sample.

To determine the concentration of phosphorus in the sample, $2.5 \mathrm{~mL}$ of the dilute solution was mixed with $2.5 \mathrm{~mL}$ Barton's reagent, then the mixture was diluted to form a total of $25.0 \mathrm{~mL}$ of yellow-colored solution. The yellow-colored solution was placed in a colorimeter set to a light wavelength of $420 \mathrm{~nm}$ to find the concentration of phosphorus in the solution.

To determine the concentration of nitrogen in the sample, $0.1 \mathrm{~g}$ of the original dry powder was mixed with $1 \mathrm{~mL}$ of sulfuric acid and kept overnight. The mixture was heated for 3 hours, and quantities of $1.5 \mathrm{~mL}$ hydrogen peroxide were intermittently added during heating until the mixture became colorless. A $40 \%$ sodium hydroxide solution was then added to digest the mixture. The digested mixture was placed in one chamber of a KEL PLUS nitrogen distillation system (manufactured by Pelican Equipments located in Chennai, India). The other chamber of the nitrogen distillation system contained $25 \mathrm{~mL}$ of boric acid. The process time of the distillation chamber was set to 5 minutes. During that period the nitrogen in the digested sample was converted to ammonia and reacted with the boric acid. The product of the reaction was then titrated with $0.02 \mathrm{M}$ sulfuric acid solution to determine the concentration of nitrogen in the original plant samples.

\subsection{Statistical Analysis}

Because this study was a proof of concept evaluation, no statistical analyses were performed on the results. Results of the measurements are presented as observed values for direct assessment of the viability of the hypothesis. 


\section{Results}

At the end of the four-week growth period, all of the plants from each DFT system were harvested and subjected to the measurement methodology described earlier. The conventional DFT system produced 14.84 grams of dry matter, while the modified (electricity-free) system produced 4.67 grams of dry matter. Although the modified system produced less dry mass, it produced a greater number of healthy plants that appeared fresher (taller and brighter green in color) based on visual inspection upon harvesting.

The conventional DFT system produced crops with percentages by weight equal to $1.18 \%$ nitrogen, $1.25 \%$ phosphorus, and $1.97 \%$ potassium. The modified DFT system produced crops with $0.98 \%$ nitrogen, $1.41 \%$ phosphorus, and $3.58 \%$ potassium (Table 2 ).

Table 2. This table summarizes the results of the experiment

\begin{tabular}{lllll}
\hline System & Dry mass (g) & \% nitrogen & \% phosphorus & \% potassium \\
\hline Conventional & 14.48 & 1.18 & 1.25 & 1.97 \\
Modified & 4.67 & 0.98 & 1.41 & 3.58 \\
\hline
\end{tabular}

\section{Discussion}

The optimal ranges of macronutrient content in plants is $2.0-5.0 \%$ for nitrogen, $0.2-0.5 \%$ for phosphorus, and $1.0-5.0 \%$ for potassium (Motsara \& Roy, 2008). This means the conventional DFT method produced plants that lacked adequate nitrogen, had excess phosphorus, and contained an optimal amount of potassium. The plants in the modified system also had the same deficiencies and excesses, but to varying degrees. The chili pepper plants in the modified system had a more severe deficit of nitrogen and a greater surplus of phosphorus. The other element contents in the plants are unknown. Furthermore, the amounts of nitrogen, phosphorus, and potassium detected only make up a very small portion of the total dry mass of the plants, so differences in the NPK contents have a minor effect on the total dry mass. Because the plants grown in the conventional DFT system had the same nutrient deficiency and excess as the plants grown in the modified DFT system, the experiment should be repeated in order to ensure that both systems provide adequate nutrients to the plants, which would then allow for a better comparison of the two systems. It may have been that the nutrient solution was not ideal for chili peppers, as limited information is available regarding hydroponically-grown chili peppers, so a better nutrient solution would provide better nutrition to the plants. In addition, the method of analysis of the NPK contents may have led to a consistent error, as the entire shoots were used when performing the NPK analysis, rather than just select leaves that would typically be used to diagnose any nutrient uptake issues.

Overall, however, the nutrient solution in the conventional DFT system had a lower EC at the conclusion of the growth period than the nutrient solution in the modified system did (Figure 6). This means that the concentration of nutrient ions in the solution was lower, so the plants may have consumed more of the nutrients. It is possible that the EC was too high for the plants in both systems, as an EC below $3.0 \mathrm{dS} / \mathrm{m}$ is considered ideal for chili pepper growth in soil. Chili peppers, however, are not severely affected by high EC and can withstand EC levels of up to $7.0 \mathrm{dS} / \mathrm{m}$ (Flynn et al., 2002). This means that there is much work left to do to fully assess electricity-free hydroponics.

While there have been no previous systematic studies of electricity-free DFT hydroponics, studies do exist on the design of inexpensive and electricity-free hydroponic systems. Alatorre-Cobos et al. (2014) developed a small hydroponic system to grow Arabidopsis and other plants. The environment the plants were grown in was highly-controlled, unlike the work in this paper. The systems constructed were also very small, as the largest system contained only $1000 \mathrm{~mL}$ of nutrient solution, so farmers would be unlikely to benefit from direct use of those systems. Some features of the Alatorre-Cobos et al. (2014) system that could be implemented on a larger scale for farmers include the use of high-density polyethylene plastic mesh to protect against pests and the use of cotton to aid in passive gas exchange (Alatorre-Cobos et al., 2014).

Successful electricity-free hydroponics in semi-controlled environments could potentially help increase the earnings of smallholder and subsistence farmers in AP and Telangana. In 2011, the average cost of electricity for domestic use in AP and Telangana was 415.38 paise per $\mathrm{kWh}$ (100 paise equals one Indian rupee, or 1 INR) (Government of India, 2014). The 2011 cost was used to approximate the cost of electricity at the time of the experiment because tariff increases in 2016 did not affect agricultural electricity consumption (Ali, 2016). The air pump used in the experiment required $35 \mathrm{~W}$ of power and was used for a total of 15 hours, meaning it used 
$0.53 \mathrm{kWh}$ of electricity. This cost INR 2.20 over the course of four weeks. Other significant initial costs necessary for the conventional DFT system were one air pump (INR 2800), 12 count of $2 \mathrm{~m}$ long air lines (INR 10 each, or INR 120 total), six air stones (INR 15 each, or INR 90 total), and one connector to attach air lines to the air pump (INR 70). This meant that the modified DFT system costs INR 3,080 (16\%) less than the conventional DFT system (Table 3).

Table 3. The cost of each item necessary for the DFT systems

\begin{tabular}{|c|c|c|}
\hline \multirow{2}{*}{ Item } & \multicolumn{2}{|c|}{ Cost (Indian Rupees, 2016) } \\
\hline & Common expenses & \\
\hline Shade net + labor & 26,000 & \\
\hline Construction labor & 4,800 & \\
\hline Watering can & 650 & \\
\hline Net pots & 392 & \\
\hline Tarp & 3,700 & \\
\hline Mulching sheet & 750 & \\
\hline Bricks + sand + cement + labor & 3,100 & \\
\hline Expanded clay pellets & 500 & \\
\hline Potassium sulfate & 40 & \\
\hline Monoammonium phosphate & 20 & \\
\hline Neem-coated urea & 15 & \\
\hline Calcium nitrate & 25 & \\
\hline Micronutrients & 138 & \\
\hline \multirow[t]{2}{*}{ Subtotal } & 40,130 & \\
\hline & Conventional & Modified \\
\hline Air pump & 2,800 & 0 \\
\hline Air lines & 120 & 0 \\
\hline Air stones & 90 & 0 \\
\hline Connector & 70 & 0 \\
\hline Total & 43,120 & 40,130 \\
\hline
\end{tabular}

With a volume- and time-limited 'proof of concept' approach, we were unable to allow the chili pepper to run its full crop cycle. Future work should include studying the full crop cycle of the chili pepper in conventional and modified DFT systems to compare the yield and quality of the fruit. The fresh mass, dry mass, nutritional composition, spiciness levels, and production cost should be analyzed. Similar experiments can also be conducted for other crops important to the cuisine of AP and Telangana, such as the staple crop rice (Government of India, 2009). The electricity-free concept should also be tested with various types of hydroponics systems. Consumer preferences should also be tested to see which system, conventional or modified, can bring the greatest profit for farmers.

\section{Conclusions}

As a means to provide support for smallholder and subsistence farmers in the semi-arid AP and Telangana regions of India, this study attempted to test the viability of a low-cost, low-tech electricity-free DFT hydroponic system. Using a simplified application of established hydroponic farming technology, this study attempted to offer a solution that could potentially enable subsistence farmers to grow crops that are viable in local climate conditions without the involvement of large expanses of agricultural land or extensive infrastructure - thus potentially reducing the overall costs and technical barriers to efficient crop production.

Operationally, the goal of the study was to compare the yield from two DFT hydroponic systems. Even though the modified DFT system produced only about a third of the dry matter as the conventional DFT system produced, electricity-free hydroponics may still be suitable for smallholder and subsistence farmers in AP and Telangana. This is because, as noted earlier, the modified system produced a greater volume of chili pepper plants that were also visually healthier than the plants from the conventional DFT system - and may indicate that the plants grown in the modified DFT system could potentially have greater commercial value in local markets, allowing greater earnings for farmers. 
In conclusion, the concept of an electricity-free, modified DFT system has the potential to become a viable option for subsistence and smallholder farmers in AP and Telangana. Reducing farmers' debts by improving their agricultural practices can save lives, making further studies towards achieving this goal not only invaluable, but also essential.

\section{References}

Alatorre-Cobos, F., Calderón-Vázquez, C., Ibarra-Laclette, E., Yon-Villalobos, L., Pérez-Torres, C. A., Oropeza-Aburto, A., ... Herrera-Estrella, L. (2014). An improved, low-cost, hydroponic system for growing arabidopsis and other plant species under aseptic conditions. BMC Plant Biology, 14(69). https://doi.org/10.1186/1471-2229-14-69

Ali, M. R. (2016). Hyderabad: Massive power tariff hike in offing. Deccan Chronicle. Retrieved June 20, 2017, from http://www.deccanchronicle.com/nation/current-affairs/090316/hyderabad-massive-power-tariff-hikein-offing.html

Baumann, P. R. (2008). The dry monsoon of the Deccan Plateau, India. Geo/SAT 2. Resource document. State University of New York College at Oneonta. Retrieved January 25, 2016, from https://www.oneonta.edu/ faculty/baumanpr/geosat2/Dry_Monsoon/Dry\%20Monsoon.pdf

Bosland, P. W., \& Walker, S. (2014). Growing chiles in New Mexico. New Mexico State University. Retrieved June 27, 2017, from http://aces.nmsu.edu/pubs/_h/H230.pdf

Flynn, R., Phillips, R., Ulery, A., Kochevar, R., Liess, L., \& Villa, M. (2002). Chili seed germination as affected by temperature and salinity. Resource document. New Mexico State University. Retrieved July 10, 2017, from http://aces.nmsu.edu/pubs/research/horticulture/CTF2.pdf

Garcia, O., Saha, A., Mahmood, K., Ndambi, A., \& Hemme, T. (2006). Dairy development programs in Andhra Pradesh, India: Impacts and risks for small-scale dairy farms. Resource document. Food and Agriculture Organization of the United Nations. Retrieved January 25, 2016, from http://www.fao.org/3/a-bp196e.pdf

Goto, E., Both, A. J., Albright, L., Langhans, R. W., \& Leed, A. R. (1997). Effect of dissolved oxygen concentration on lettuce growth in floating hydroponics. Acta Horticulturae, 440, 205-210.

Government of India. (2009). Post harvest profile of chilli. Ministry of Agriculture (Department of Agriculture and Cooperation), Government of India. Retrieved June 28, 2016, from http://agmarknet.gov.in/Others/ preface-chhilli.pdf

Government of India. (2014). State-wise average rate of electricity for domestic and industrial consumers. Open Government Data Platform, Resource document. Government of India. Retrieved June 26, 2017, from https://data.gov.in/catalog/state-wise-average-rate-electricity-domestic-and-industrial-consumers

Government of India. (2016). Know India: Andhra Pradesh. National Portal of India. Government of India. Retrieved June 15, 2016, from http://www.aponline.gov.in/apportal/Index.asp

Government of India. (2017). Know India: States and union territories. National Portal of India. Government of India. Retrieved April 14, 2017, from http://knowindia.gov.in/knowindia/state_uts.php

Government of Telangana. (2017). History. Telangana State Portal. Government of Telangana. Retrieved April 14, 2017, from http://www.telangana.gov.in/About/History

Jensen, M. H., \& Malter, A. J. (1995) Protected agriculture: A global review. World Bank Technical Paper 253 (p. 157). World Bank Publications.

Kubota, C., \& Kroggel, M. (2015). Strawberry production costs in greenhouse. University of Arizona. Retrieved February 2, 2016, from https://cals.arizona.edu/strawberry/Hydroponic_Strawberry_Information_Website/ Costs.html

Larson, G., \& Williams, M. (2012) A rural institutional platform mobilizes communities to become effective partners in agricultural innovation in Andhra Pradesh. Agricultural Innovation Systems: An Investment Sourcebook (p. 639). The World Bank.

Majumdar, B. (2015). Telangana, AP could face $50^{\circ} \mathrm{C}$ as water, green cover depletes: Experts. The Times of India. Retrieved June 25, 2017, from http://timesofindia.indiatimes.com/india/Telangana-AP-could-face-50-C-aswater-green-cover-depletes-Experts/articleshow/47464272.cms

Mattson, N. S., \& Peters, C. (2014). A recipe for hydroponic success. Inside Grower. Ball Publishing. Retrieved June 26, 2017, from http://www.greenhouse.cornell.edu/crops/factsheets/hydroponic-recipes.pdf 
Motsara, M. R., \& Roy, R. N. (2008). Guide to laboratory establishment for plant nutrient analysis. Resource document. Food and Agriculture Organization of the United Nations. Retrieved July 5, 2017, from ftp://ftp.fao.org/agl/agll/docs/fpnb19.pdf

Pokharel, S. (2015). Why India's cotton farmers are killing themselves. CNN World. Retrieved January 23, 2016, from http://www.cnn.com/2015/04/19/asia/india-cotton-farmers-suicide/index.html

Qaim, M., \& Kouser, S. (2013). Genetically modified crops and food security. PLoS ONE, 8(6), e64879. https://doi.org/10.1371/journal.pone.0064879

Shrestha, A., \& Dunn, B. (2016). Hydroponics. Resource document. Oklahoma State University. Retrieved June February 1, 2016, from http://pods.dasnr.okstate.edu/docushare/dsweb/Get/Document-6839/HLA-6442 web.pdf

US Geological Survey. (2017). Water properties: Dissolved oxygen. Retrieved June 26, 2017, from https://water.usgs.gov/edu/dissolvedoxygen.html

\section{Copyrights}

Copyright for this article is retained by the author(s), with first publication rights granted to the journal.

This is an open-access article distributed under the terms and conditions of the Creative Commons Attribution license (http://creativecommons.org/licenses/by/4.0/). 